\title{
Challenges in public health facilities and services: evidence from a geographically isolated and disadvantaged area in the Philippines
}

\author{
Zaldy C Collado \\ ${ }^{1}$ Behavioral Science Department, De La Salle University, Manila, Philippines \\ Keywords: global health \\ https://doi.org/10.29392/joghr.3.e2019059
}

Journal of Global Health Reports

Vol. 3, 2019

\section{Background}

The study describes the conditions of public health sector in the Island Municipality of Jomalig, Quezon Province in Luzon, Philippines. Located at the far north-eastern side of the Quezon Province, Jomalig Island can be reached through a motor boat at around 4-5 hours (or more depending on the sea condition). Given the geographical disadvantage, challenges in economic and social services in the island are apparent. That includes deficiencies in basic public utility services such as water and electricity. The paper showcases a needs assessment on public health facilities and services in a far-flung municipality in the Philippines. This study examines the challenges in public health aspirations in a location considered to be a geographically isolated and disadvantaged area (GIDA).

\section{Methods}

The study made use of key informant interviews (KIIs) among health professionals and village health workers in the island. Aside from the KIIs, the study included the World Health Organization's (WHO) tracer checklist on general readiness. The checklist was administered but in interview style. The participants were the public health staff in the island. The researcher was able to interview the health professionals (nurses and a midwife) manning the main public health facility in the island municipality while in the case of the other villages, health volunteers or the Barangay Health Worker (BHWs) were interviewed.

\section{Results}

There are deficiencies in facilities, offered services and health staff. Deficiencies are seen too based on the domains under the WHO Tracer Checklist. Mortality and morbidity rates were not at alarming rate though reports of hypertension and diarrhea are common. The relatively "complete" health services are only available at the island's main health center yet unfortunately, some people who seek treatment and health care could not visit due to distance and the accompanying expenditures. Other factors affecting health status of the population include the reliance to "faith healers" (quack doctors or Albularyos) and the delay of parental reports of their health condition and the condition of their children, both of which result to the "escalation" of illness. Among others, challenges and aspirations of the island's public health sector include electric supply, better budgetary allocation for their facilities, and equipment and additional training for the barangay (village) health workers.

\section{Conclusions}

Enduring the underfinanced and undermanned health facilities, the island's population also suffers the consequences on overall health owing to limited movements and communication due to the geographical characteristics of the municipality. Emergency boats per village, health education campaign that focuses on eliminating open defecation and reliance on quack doctors, stand-by generators for the health centers, and radio communication system are strongly recommended to mitigate the negative impacts of living within GIDA communities. 
High incidence of poverty is recorded in far-flung areas, which also comes with households having greater chances of living in poor conditions for a long time. In addition, geographically isolated areas are also associated with poor basic services and facilities such as schools, sanitation, electricity and clinics or health centers. ${ }^{1}$ Some of these conditions have led to the deaths of poor children ${ }^{2}$ or have put them in poor health conditions. ${ }^{3}$ Moreover, positive health-seeking behaviour are not observed among the poor in contrast to population of higher economic classes. ${ }^{4}$ This is not surprising since the less fortunate succumb to the consequences of poverty as they suffer the incapability to cope with health expenditures. ${ }^{5}$ That is why community economic development is a crucial component in forming health-seeking behaviour 6 in these very areas. Governments have pursued nonetheless strategies to encourage the poor to utilize health facilities and services like giving incentives 7,8 and enrolling them in social insurance schemes. ${ }^{9}$

However, aside from poverty, the conditions of public health facilities including the quality of health professionals and workers determine also the trajectories of health outcomes. ${ }^{10}$ While, for example, improved access to better public health facilities and their services can reduce the mortality and morbidity rates associated with unhygienic medical procedures ${ }^{11}$, some health workers were found out to be prescribing drugs despite being untrained to do so 12 , which could lead to serious health complications among the public. Indeed, public health facilities and services are marred with concerns. Aside from the infrastructural and training aspects, problems in human resources and leadership contribute negatively to health-related services. ${ }^{13}$ Such findings echoed what was underscored in the earlier study ${ }^{14}$ where poor management in the provincial and local level were found out to be contributory to low-quality service in these health facilities.

Obviously, geographically isolated and disadvantaged areas (GIDA) reveal not only deficiencies in health facilities and services but also to the number of people accessing them compare to urban, city spaces. Policy makers should concern themselves to health outcomes especially in the midst of this gross inequalities. ${ }^{15}$ Unfortunately, policy makers have rarely focus on including the poor in the implementation and formulation of strategies. ${ }^{16}$

GIDA areas in the Philippines are particularly suffering under these conditions. Aside from the lack of health facilities (or the deficiencies therein), health professionals are either concentrated in the urban areas or leaving the country. ${ }^{17}$ Despite the shortage of health professionals, the Philippines continue to be a major exporter of such human resources. ${ }^{18}$ Inadequate pay is identified as one of the reasons health personnel are considering leaving public health facilities. ${ }^{19}$

With all these on the background, the study examines the health needs of a far eastern island municipality in the Philippines. This aims to explore the deficiencies in health facilities and services in the island and how its location contributes significantly in the overall health-seeking behavior and health status of the population. The study provides insights as to how these geographically isolated and disadvantaged areas are challenged in terms of the desires to health care services and to recommend potential "small" solutions while recognizing budgetary constraints on the part of the government.

\section{METHODS}

\section{STUDY LOCATION}

The research locale was the Island Municipality of Jomalig, part of the Quezon Province in Luzon, Philippines. Located at the far north-eastern side of the Quezon Province, Jomalig Island can be reached through a motor boat at around 4-5 hours (or more depending on the sea condition). Given the geographical disadvantage, challenges in economic and social services in the island are apparent. That includes deficiencies in basic public utility services such as water and electricity. In addition, most roads are not yet cemented which can turn easily into mud during rainy seasons. Health centers are visited by a doctor once or twice a month. The Philippine Statistics Authority indicates that Jomalig is a 5 th class municipality which means that the locality has an annual income of 1 to 3 million pesos only.

\section{PARTICIPANTS}

The participants of the study were basically the public health staff in the island. The researcher was able to interview the health professionals (nurses and a midwife) manning the main public health facility in the island municipality while in the case of the other villages, only health volunteers or the Barangay Health Worker (BHWs) were interviewed. Some village officials were also able to give information about the status of their health facilities and services through informal conversations.

\section{DATA COLLECTION}

The data were gathered through Key Informant Interviews (KIIs) with the assigned health professional (nurse or midwife) and the Barangay Health Worker (BHWs) for each particular barangay or community. The KIIs also made use of the World Health Organization's Service Availability and Readiness Assessment (SARA) on general service readiness indicators. ${ }^{20}$ The researcher made used of this WHO Tracer (Appendix S1 in the Online Supplementary Document) to survey the level of general readiness of this island's facilities to cater the health needs of its population. Each KII took place inside the health center "facilities". The KII had two parts, the first was on the open-ended questions that inquired about the conditions of public health facilities in the area and the consequences of which in the general health of the population. The second part was on answering the WHO Tracer.

\section{ANALYSIS}

The data obtained from the KII were transcribed and then thematically analyzed. The result of WHO tracer checklist is presented in prose form under the given domains of the checklist. 


\section{ETHICAL APPROVAL}

The researcher secured prior approval before the actual gathering of data among the participants. The researcher asked the permission of the head of the main health center of the island before the actual conduct of KII with their health staff in the center and in other villages. Aside from securing permission to conduct KIIs with the BHWs, the researcher also asked and informed each respective village official (village captain) about the undertaking. The researcher also sought the permissions of the participants about the use of a voice-recording device.

\section{RESULTS}

Key findings of this research are divided into several categories: (a) Mortality and Morbidity Rates (b) Health Services (c) Other factors affecting health status of the population (d) Challenges and Aspirations, and (e) WHO Tracer Items for assessing general readiness. These results are presented according to the themes that emerged from the interviews.

\section{MORTALITY AND MORBIDITY RATES}

All barangays reported no alarming rates of mortality. Rare are cases of mortality due to illnesses but some minimal cases of death are reportedly due to natural death and hypertension. Consistently, all Barangays recorded cases of ordinary colds and cough and especially diarrhea. In two Barangays, Casuguran and Gango, health professionals noticed increased complaints of children's wounds. The changing weather in the island is seen as a strong factor that causes colds and cough among children. The striking consistency of diarrhea in these communities is attributed to the open defecation practices of some residents in farflung communities (in sitios or sub-villages]. Health professionals believe that such a practice contaminates the water source below and even in the seas where they just throw their faeces:

“They will just go somewhere private and defecate there. Some others would put their human waste in the plastic bag and then throw it in the waters. It made their water supply contaminated and especially diarrhea is more common to children who play and swim in the contaminated waters."

\section{HEALTH SERVICES}

Common to all Barangays are the general consultation services (with BP Monitoring], in which, health professionals sometimes are "forced" to issue prescription due to the absence of doctor in the island. Some minor surgeries can also be done in these health centers but are protocoled to be done in the main health center in Barangay Talisoy. Family planning, including its free counselling and contraceptives, is also offered in all Barangays. Deworming and immunization are also consistently offered and done in the health centers. However, in a sitio (sub-village) in Barangay Casuguran, immunization was not consistently held due to the lack of proper refrigeration for the vaccines. People in that Sitio could not just go in the Health center of their Barangay because of the travel cost and distance. Pre-natal check-ups are also offered in the centers with the lying-in services except in Barangay Bukal. Feeding programs are also held in Barangays Gango and Casuguran to counter malnutrition. TB dots program as well as the Grantisadong Pambata Program (Immunization) are offered in the centers. Anti-rabies shots are not offered even in Barangay Talisoy, so people have to go to Polilio or Lucena (Other Towns in the Province) for such injections.

\section{OTHER FACTORS AFFECTING HEALTH STATUS OF THE POPULATION}

a. Albularyo-based treatment and other old beliefs and practices - Some part of the population still prioritise going to quack doctors over health professional and the BHWs for proper medical treatment. The implication is that those who came to Albularyos (faith healers) first then go to the health centers afterwards had their health conditions deteriorate or worsen. The idea of going first to Albularyos is reinforced by the belief that when people go to health centers, something bad will happen. A health professional also reported about people pouring amoxicillin to their open wounds instead of taking it in. Thus, wounds are not treated properly. Pregnant women also choose hilot (a birthing method characterized primarily by "massage") over health center's lying-in for proper birth delivery, which sometimes results to maternal and child death.

b. Poverty/Lack of income - the economic status of the general population spells a lot about the health status of people. It resulted to malnourishment of children, in fact in 2012, DSWD lists Jomalig as one of the top municipalities which have severe case of malnourishment among children. Money becomes also a terrible problem with the locals because they just cannot travel to their health center (in case they are from sitios going to the center) or from the island going to hospitals in other municipalities and cities of the Quezon province. Habal-habal (motorcycle - local mode of transportation) is also costly at the rate of hundreds, as well as the boat from the island going to other towns (especially if it's a special trip) just to seek medical attention.

c. Geographical location and sea conditions - the distance to better health facilities also has great impact to the overall health status of the population. Intensive medical attention and comprehensive check-up are just few of the things that cannot be accessed easily due to proximity of the people from these facilities, its cost and travel hours make health needs more challenging to access for the poor population. Taking also into account the sea conditions, people just cannot sail even in emergency situations due to safety concerns, leaving patients in a very difficult position. Weather also is believed to be of a significant factor. Health workers attributed cases of cough and colds to the changing weather in the island.

d. Environment - unclean water sources are also factors in some communities due primarily to open defecation practices of some locals. Aside from irresponsible garbage dumping, the interviewees revealed that there are communities that almost half of the total number of households has no toilets of their own, affecting ground water below and even the immediate sea water close to those communities. 
e. People's stubbornness - parents play cards during the day that their children are left outside playing, in which they usually left these children unmonitored on their recreational activities in dirty areas and in the sea. Health workers believe that such is one of the causes why commonly complaint illnesses including wounds among children persist. This stubbornness also led to some parents consulting or bringing their children during evening or night when the official time of health workers has already passed but which ultimately results to the illnesses not being assessed earlier, and therefore not treated in its supposedly earlier stage.

\section{CHALLENGES AND ASPIRATIONS}

a. Electricity - Supply of electricity has always been the challenge. In five Barangays, limited electricity negatively impacts health care services in the centers. Barangay Talisoy enjoys at least a consistent electric supply during 8AM to $5 \mathrm{PM}$ services due to the generator. Lying-ins in those barangays, thus, become not ideal place for those who are about to give birth.

b. Equipment and facilities - three out of the two barangays do not have a health center on their own. Those three barangays were offered to only use a vacant room inside their Barangay hall (Village Local Office). Except for the main health center, the other four centers have no adequate facilities and own source of water for sanitation purposes. Most of the lying-ins are only in their structural form, however, beds and other equipment related to lying-in services are lacking. Medicines and equipment, especially for emergency situations are also lacking and insufficient such as nebulizers for some Barangays. Even adult scale to be used for mothers is also lacking in some Barangays.

c. Transportation - vital emergency transportation both in land and sea is also not available for the general population. Thus, health services are severely affected in terms of bringing patients to the main health center and even to some hospitals in the Quezon province. A nurse proposed that at least one emergency fast craft boat be deployed in the Island in case of emergency.

d. Barangay health workers - some health workers (health professionals and BHWs) believe that the training for BHWs is insufficient and thus more training is needed. One thing that sometimes discourage BHWs from attending training is the transportation cost when going to the main health center. A health professional from Barangay Bukal proposed that the honorarium should be raised from its value, in 2015 , of Php. 500.00 or US\$9.61.

e. Health professionals (nurses and midwives) - part of the struggle in the island for these health professionals is their extended working hours. Supposedly from 8AM to $5 \mathrm{PM}$ only, their doors are knocked even in the evening for consultations.

The WHO Tracer Items for assessing general readiness, presented in five domains (basic amenities, basic equipment, standard precaution for prevention of infections, laboratory and medicine and commodities).

\section{A) BASIC AMENITIES}

Health centers in the island during supposedly working hours do not have electric supply. Only Barangay Talisoy out of five Barangays, being the main health center in the island, enjoys a generator at times. It also lacks improved water source;

"Our health center cannot be said to have improved wa-
ter source since we only rely on underground source of
water"

Only three out of five health centers have rooms for a private patient consultation. Only one among all the barangay health centers has no access to adequate sanitation facility. All health centers in the island have no communication equipment. Instead they use their own personal phones to contact health authorities outside the island and within. However, only Barangay Talisoy has a good network signal, other areas in the island either has no or fluctuating signal, making reporting of health cases for the health workers difficult. One health professional even narrated that one time he really struggled to report and ask for a medical advice from the doctor when a resident was accidently hit in the face with a fallen coconut;\#:

"It was really difficult. We need instructions from a doctor but we could not communicate."

Additionally, health centers have no computers. Email and internet are only accessible (with considerable degree of difficulty) through the health workers' personal phones and laptops. The Island has no emergency vehicle.

\section{B) BASIC EQUIPMENT}

Generally, all health centers except one, Barangay Gango, have adult scales while child/Infant scale, thermometer, stethoscope and sphygmomanometer are available to all villages. Only the main health center has a refrigeration equipment. This is the reason why some vaccines are only accessible to the main health center:

"People from other villages have no choice but to go here in the town center for vaccination. All vaccines are here because other health centers have no refrigerators."

Two of the Barangay health centers, Barangay Bukal and Apad, mentioned that they only use natural light source, all others are with available generators.

\section{C) STANDARD PRECAUTION FOR PREVENTION OF INFECTIONS}

Sterilization equipment is available only at the main health center while all health centers (including the main] have adequate storage and disposal of sharps, sharps box/container, disinfectant, single use - standard disposable syringes, latex gloves and masks. Unfortunately, soap or hand disinfectant storage and safe disposal of infectious wastes are not adequate even in the main health center. The guidelines for standard precaution is available only at Barangay Talisoy. 


\section{D) LABORATORY}

Almost all health centers in the island have no basic laboratory test equipments and paraphernalia. Except for the main health center which can cater whole blood glucose by glucometer, urine dipstick and urine pregnancy test, all others have none. The tracer checklist provided 9 basic laboratory items for general readiness, thus only 3 among those 9 are said to be readily available in the island, specifically in the main health center in Barangay Talisoy.

\section{E) MEDICINE AND COMMODITIES}

Of these standard 14 essential medicines, only three are not available in the main health centers such as the Atenolol, Amitriptyline and Ceftriaxone. The available medicines in the main health center are generally available also in the health centers in other Barangays. The availability of the most number of these medicines from the checklist means that, in so far as the item for medicines and commodities are concerned, there is relatively general readiness.

\section{DISCUSSION}

The island municipality is far from being an ideal place to have a medical treatment, even to be sick. Aside from health centers being underequipped and undermanned, infrastructures such as roads and health facilities in the Island cannot be said to have a supporting environment to cater quality health services. Health centers in the area could only respond and treat to basic illnesses that require no complex medical procedures and medication. At the end of the day, patients with deeper health issues as well as those with emergency cases that require major surgery and immediate medical attention still have to seek help outside Jomalig. Dental services are not also available.

Travel costs, distance, transportation and poor network signal in some areas all play roles leading to mortality and morbidity among the population. Among the very poor people, who are also the most vulnerable to sickness in Jomalig, is the struggle to report their illnesses at times due to expensive travel cost from the sitios to health centers. Even if they are able to consult health professionals in their respective health centers, cases which have to be treated somewhere else like in Lucena, Polilio, and Panganiban or in Manila are left in the same status since travelling is costly, how much more the cost of having to be treated. They even have term called "pasahirap" to refer to free ride boat passengers. This is why transportation system is a crucial strategy in serving socially excluded population. ${ }^{21}$ Not only the distance affects negatively the population to access health services but also the services being done and offered by health workers. Some BHWs are reportedly not so consistent in attending training sessions and reporting cases in their respective areas due to the travel cost. In emergency cases also, availability of transportation and the distance are all crucial factors for attending to the patients' needs. Added to this is the status of network signal in the island. Communication between health authorities in the island is hampered by poor or even absent signals in some areas. Immediate medical advice and other related medical instruc- tions are not followed immediately because of poor signal in some areas, thus putting peoples' health and life at risk.

Other factors that negatively affect the health status of population are beliefs which are counter-scientific in nature and those that exhibit people's stubbornness. Albularyos are flourishing and people are buying their services that sometimes led to the "escalation" of illness. People's attitude also in terms of sanitation, of practicing open defecation despite local authorities' intervention, grows problematic as cases of diarrhea increase also. Thus, peoples' unwillingness to health measures in the island has compounded the already fragile health services provided by the health centers.

The health services in the island are therefore far from being perfectly dependable. In the World Health Organization (WHO) tracer for general readiness, the island's health centers can be said to have limited capacity. The absence of electricity, strong communication signal, emergency transport, proper facilities and basic lab tests have all been part of the struggles of health workers to deliver efficient and quality health services. However, to mitigate the impact of having not so effective health services in the island, the population must start to work on better environment and eradicate old popular beliefs that are not helpful in sustaining positive health outcomes. By transforming those sets of beliefs and practices into behaviors consistent with attempts to achieve good health and preservation of life, health centers in the island can monitor more effectively the real health status of people within their jurisdiction, save government resources and help more patients in the process.

\section{METHODOLOGICAL LIMITATIONS}

Readers are asked to take caution in the appreciation of the findings. The data used on this article lifted up from a fieldwork done in 2015. Three years have passed since the last time the researcher visited the particular communities under consideration. Since then, public health facilities and services may have been improved and do not now reflect the current conditions. Nonetheless, these reports are still relevant in public health discussions with special attention on rural health.

\section{CONCLUSIONS}

Given these results, the island municipality has apparent deficiencies in public health facilities and services which obviously led to poor health outcomes and health-related practices among the population. The government has to quickly act on financing facilities including the additional and training of health staff in GIDA areas in order to effectively provide just even the most minimum of quality health service. Emergency boats per village, health education campaign that focuses on eliminating open defecation and reliance on quack doctors, stand-by generators for the health centers, and radio communication system are strongly recommended. 


\section{ACKNOWLEDGEMENTS}

The researcher is forever grateful to Tatay Erning $(+)$ who died this year (2019) in one of the health centers in the Island. He was the habal-habal (single motorcycle) driver who accompanied and serviced the researcher going and traversing difficult, muddy roads to every village of the island.

\section{FUNDING}

None.

\section{COMPETING INTERESTS}

The author completed the Unified Competing Interest form at http://www.icmje.org/coi disclosure.pdf (available upon request from the corresponding author), and declare no conflicts of interest.

\section{CORRESPONDENCE TO:}

Zaldy C Collado

Social Development Research Center

De la Salle University

2401 Taft Ave

Malate

Manila, 1004

Philippines

zaldy_collado@dlsu.edu.ph 


\section{REFERENCES}

1. Bird K, McKay A, Shinyekwa I. Isolation and poverty: The relationship between spatially differentiated access to goods and services and poverty. Overseas Development Institute. Published online 2010. Accessed March 9, 2019. https://www.od i.org/sites/odi.org.uk/files/odi-assets/publications-op inion-files/5516.pdf

2. Bartram J, Cairncross S. Hygiene, sanitation, and water: Forgotten foundations of health. PLoS Med. 2010;7(11):e1000367. doi:10.1371/journal.pmed.1000 $\underline{367}$

3. Gertler P. Do conditional cash transfers improve child Health? Evidence from PROGRESA's Control Randomized Experiment. Am Econ Rev. 2004;94(2):336-341. doi:10.1257/0002828041302109

4. Schellenberg JA, Victora CG, Mushi A, et al. Inequities among the very poor: health care for children in rural southern Tanzania. Lancet. 2003;361(9357):561-566. doi:10.1016/s0140-6736(0 3) $12515-9$

5. Onwujekwe O, Hanson K, Uzochukwu B. Examining inequities in incidence of catastrophic health expenditures on different healthcare services and health facilities in Nigeria. PLOS ONE.

2012;7(7):e40811. doi:10.1371/journal.pone.0040811

6. Stephenson R, Baschieri A, Clements S, Hennink M, Madise N. Contextual influences on the use of health facilities for childbirth in Africa. Am J Public Health. 2006;96(1):84-93. doi:10.2105/ajph.2004.057422

7. Lim SS, Dandona L, Hoisington JA, James SL, Hogan MC, Gakidou E. India's Janani Suraksha Yojana, a conditional cash transfer programme to increase births in health facilities: an impact evaluation. Lancet. 2010;375(9730):2009-2023. doi:10.1016/s014 0-6736(10)60744-1

8. Rasella D, Aquino R, Santos CA, Paes-Sousa R, Barreto ML. Effect of a conditional cash transfer programme on childhood mortality: a nationwide analysis of Brazilian municipalities. Lancet. 2013;382(9886):57-64. doi:10.1016/s0140-6736(13)60 715-1

9. Wagstaff A. Social Health Insurance Reexamined. World Bank Policy Research Working Paper 4111. The World Bank; 2007. doi:10.1596/1813-9450-4111
10. Rowe AK, Onikpo F, Lama M, Cokou F, Deming MS. Management of childhood illness at health facilities in Benin: Problems and their causes. Am J Public Health. 2001;91(10):1625-1635. doi:10.2105/ajp $\underline{\text { h.91.10.1625 }}$

11. Paul BK, Rumsey DJ. Utilization of health facilities and trained birth attendants for childbirth in rural Bangladesh: an empirical study. Soc Sci Med. 2002;54(12):1755-1765. doi:10.1016/s0277-9536(01)0 $\underline{0148-4}$

12. Zhan SK, Sheng-Lan T, You-De G, Bloom G. Drug prescribing in rural facilities in China: Implications for service quality and cost. Trop Doct. 1998;28(1):42-48. doi:10.1177/004947559802800112

13. Coovadia H, Jewkes R, Barron P, Sanders D, McIntyre D. The health and health system of South Africa: historical roots of current public health challenges. Lancet. 2009;374(9692):817-834. doi:10.1 016/s0140-6736(09)60951-X

14. Garner P, Thomason J, Donaldson D. Quality assessment of health facilities in rural Papua New Guinea. Health Policy Plan. 1990;5(1):49-59. doi:10.10 93/heapol/5.1.49

15. Marmot M. Social determinants of health inequalities. Lancet. 2005;365(9464):1099-1104. doi:1 $\underline{0.1016 / \mathrm{s} 0140-6736(05) 74234-3}$

16. Peters DH, Garg A, Bloom G, Walker DG, Brieger WR, Rahman MH. Poverty and access to health care in developing countries. Ann N Y Acad Sci. 2008;1136(1):161-171. doi:10.1196/annals.1425.011

17. Senate of the Philippines. Rural areas suffer most from poor health Care system, says Angara: Seeks to bridge urban-rural gap through Telehealth system. Press Release. Published online May 27, 2009. http s://www.senate.gov.ph/press_release/2009/0527_anga ra1.asp

18. Romualdez A Jr, de la Rosa J, Flavier J, Quimbo S, Hartigan-Go K, Lagrada L, et al. The Philippines Health System Review. Health Systems in Transition. Published online 2011. Accessed March 9, 2019. htt p://www.wpro.who.int/philippines/areas/health syste ms/financing/philippines health_system review.pdf

19. Penn-Kekana L, Blaauw D, Tint K, Monareng D, Chege J. Nursing Staff Dynamics and Implications for Maternal Health Provision in Public Health Facilities in the Context of HIV/AIDS. Frontiers in Reproductive Health. Population Council; 2005. Accessed March 9, 2019. https://doi.org/10.31899/rh4.1205 
20. World Health Organization. Service Availability and Readiness Assessment (SARA) An annual monitoring system for service delivery: Reference Manual. Version 2.1. Published online September 2013. https://www.who.int/healthinfo/systems/sara_r eference_manual/en/
21. Church A, Frost M, Sullivan K. Transport and social exclusion in London. Transp Policy. 2000;7(3):195-205. doi:10.1016/s0967-070x(00)0002 $4-\mathrm{x}$ 